\title{
Vaginal dose of radical radiotherapy for cervical cancer in China: a multicenter study
}

\author{
Juan Wang ${ }^{1 \dagger}$, Kai-shuo Zhang ${ }^{1 \dagger}$, Tao Wang ${ }^{1}$, Zi Liu ${ }^{1 *}$ (D), Rui-hua Wang ${ }^{1}$, Fu-quan Zhang ${ }^{2}$, Lang Yu², Li Ran³, \\ Jian-li He ${ }^{4}$, Ya-li Wang ${ }^{5}$, Li-chun Wei ${ }^{6}$, Mei Shi ${ }^{6}$, Guo-qing Wang ${ }^{7}$, Chao-qun Wu ${ }^{8}$, Qi-jun Kang ${ }^{8}$, Jie Yang ${ }^{9}$, Sha Li ${ }^{10}$, \\ Fei-yue Yang ${ }^{11}$, Bao-gang Liu ${ }^{12}$, Juan-yue Liu ${ }^{13}$, Fan Shi', Jin Su' ${ }^{1}$, Wei Yuan ${ }^{1}$ and Emmanuel Kwateng Drokow ${ }^{1}$
}

\begin{abstract}
Background: The posterior-inferior border of symphysis (PIBS) point system is a novel vaginal dose-reporting method and is a simple and reliable method proposed by the Medical University of Vienna proposed for both external-beam radiotherapy (EBRT) and brachytherapy (BT). In this multicenter study, we sought to first evaluate the vaginal radiation dose in Chinese cervical cancer patients according to the PIBS point system and then to analyze the factors influencing the dose distribution.

Methods: We collected data from the medical records of 936 cervical cancer patients who underwent concurrent radiochemotherapy at 13 different institutions in China. Radiation doses at points A, PIBS+ $2 \mathrm{~cm}, \mathrm{PIBS}$ and PIBS-2 cm, International Commission on Radiation Units (ICRU)-R and ICRU-B were measured.

Results: The median total doses in $\mathrm{EQD} 2_{\alpha / \beta=3}$ at points PIBS+ $2 \mathrm{~cm}$, PIBS and PIBS-2 cm were 82.5 (52.7-392.1) Gy, 56.2 (51.4-82.1) Gy and 2.6 (0.9-7.4) Gy, respectively. The median total doses in EQD $2_{\alpha / \beta}=3$ at ICRU-R and ICRU-B were 77.5 (54.8-132.4) Gy and 79.9 (60.7-133.7) Gy, respectively. The mean vaginal reference length (VRL) was $4.6 \pm$ $1.0 \mathrm{~cm}$ (median, $4.5 \mathrm{~cm}$ ). In patients with VRL $\leq 4.5 \mathrm{~cm}$, the mean total doses in EQD $2_{\alpha / \beta=3}$ at points PIBS+ $2 \mathrm{~cm}$, PIBS and PIBS- $2 \mathrm{~cm}$ were 128.5, 60.7 and $0.8 \mathrm{~Gy}$, respectively. In patients with VRL $>4.5 \mathrm{~cm}$, the mean total doses at these three points were $68.9,0.5$ and $54.5 \mathrm{~Gy}$, respectively. Classification of patients revealed significant differences $(P<0.05)$ between these two groups.

Conclusions: With the PIBS point system, Chinese patients with a shorter VRL of $<4.5 \mathrm{~cm}$ received higher radiation doses at the PIBS+ $2 \mathrm{~cm}$, PIBS and PIBS- $2 \mathrm{~cm}$ points than European and American patients. Further studies are required to establish the dose-effect relationships with these points as references.

The study was registered as a clinical trial (NCT03257475) on August 22, 2017.
\end{abstract}

Keywords: Cervical cancer, Radiotherapy, Vaginal dose, PIBS

\section{Background}

Locally advanced cervical cancer, which is classified as stage $\geq$ IB2 as per the International Federation of Gynecology and Obstetrics (FIGO) criteria, is treated with a concurrent radiochemotherapy. Radiotherapy involves the administration of pelvic external-beam radiotherapy (EBRT) as well as

\footnotetext{
* Correspondence: liuzmail@163.com

†uan Wang and Kai-shuo Zhang contributed equally to this work.

${ }^{1}$ Department of Radiation Oncology, The First Affiliated Hospital of Xi'an Jiao

Tong University, 277\# West Yanta Road, Xi'an, Shaanxi, China

Full list of author information is available at the end of the article
}

brachytherapy (BT). However, in cases of locally advanced cervical cancer, the upper part of the vagina is considered a target organ for radiotherapy, which puts the higher part of the vagina at risk of radiotherapy-induced injury. Despite this, investigations on vaginal morbidity after radiotherapy have been scarce.

Our previous analysis on vaginal morbidity in cervical cancer patients treated with the current treatment strategies revealed that the incidence of vaginal radiation injury was $84.4 \%(238 / 282)$, and the incidence rates of radiation injury of grades II, and III were $29.8 \%(84 / 282)$

(c) The Author(s). 2019 Open Access This article is distributed under the terms of the Creative Commons Attribution 4.0 International License (http://creativecommons.org/licenses/by/4.0/), which permits unrestricted use, distribution, and reproduction in any medium, provided you give appropriate credit to the original author(s) and the source, provide a link to the Creative Commons license, and indicate if changes were made. The Creative Commons Public Domain Dedication waiver (http://creativecommons.org/publicdomain/zero/1.0/) applies to the data made available in this article, unless otherwise stated. 
and $3.9 \%(11 / 282, P<0.05)$, respectively [1]. Kirchheiner et al. found that vaginal morbidity occurred in 255 of $630(40.5 \%)$ patients, with morbidity rates for grades II and III being 17, and 1\%, respectively [2]. Similarly, Susko et al. found that of the morbidity rates for grades II and III or higher vaginal toxicity were 41.7 and $17.6 \%$, respectively, in 36 of 62 cervical cancer or uterine cancer patients [3]. Multi-factor analysis indicated that the dose of BT was an independent factor affecting the occurrence of vaginal radiation-induced injury $(P=0.043)$ [1].

To identify a simple and reliable representation of the radiation exposure in the vagina and establish a method suitable for both EBRT and BT, the Medical University of Vienna proposed a novel vaginal dose-reporting method [4]. This method allows for the determination of the total (EBRT+BT) dose (EQD2) administered to the upper, mid, and lower parts of the vagina. Further, this evaluation system can be used for 2D and 3D BT. In this study, we sought to test the applicability of this method in Chinese patients and determine the vaginal dose administered in patients, with a view to identifying the influencing factors for vaginal radiation injury in the future.

\section{Methods}

This investigation was designed as an observational study of patients who underwent concurrent radiochemotherapy at any of the 13 participating hospitals between December 2016 and June 2018. The study was registered as a clinical trial (NCT03257475) and approved by the ethics committee of the First Affiliated Hospital of Xi'an Jiaotong University (No. XJTU1AF2017LSK-11). Informed consent was obtained from all patients who participated in this study.

In all, we selected 936 of the 1194 cases, for which complete data were available, excluded 30 patients for lack of complete clinical information and exclued 228 patients aged $>60$ years, since elasticity and length of the vagina are affected by estrogen level. All patients were diagnosed with cervical carcinoma of stages IIA1 to IVB (except for IIIA), classified as per the 2009 FIGO criteria [5]. Twelve patients who had enlargement of para-aortic lymph nodes received extended field radiation. EBRT was delivered to the entire pelvis at 1.8-2.0 Gy per fraction, for a total of 25 fractions and 45-50 Gy (3D-conformal radiotherapy [CRT] or intensity-modulated radiotherapy [IMRT]), with concurrent weekly administration of cisplatin $\left(25 \mathrm{mg} / \mathrm{m}^{2}\right.$, [6] or cisplatin $\left(25 \mathrm{mg} / \mathrm{m}^{2}\right.$, day 1-day 3) combined with liposome paclitaxel $\left(135 \mathrm{mg} / \mathrm{m}^{2}\right.$, day 1$)$. The target was contoured according to recommendations of the Radiation Therapy Oncology Group (RTOG) with threedimensional (3D) computed tomography (CT)-assisted treatment planning [7].

High-dose rate (HDR) BT was administered at doses of 24 or $30 \mathrm{~Gy}$ in 4 to 5 fractions after EBRT using the Fletcher-Suit-Delclos set with a microSelectron HDR
(Elektra Brachy, Sweden).The planning aim at point A was 82-90 Gy in EQD2. BT was administered via the CT/ simulation (CT/SIM)-guided technique with a tandemovoid applicator. A CT/SIM scan of the pelvis was performed in the first and third BT fractions. The obtained images were transferred onto Oncentra TPS. For treatment planning, the point A dose-evaluation method was used, with the loading dose based on the Manchester system of BT, with the objective of delivering $6 \mathrm{~Gy}$, which at EQD2 was 8 Gy to point A. A sum of the BT and EBRT doses was determined applying the linear-quadratic model, with an $\alpha / \beta$ ratio of $10 \mathrm{~Gy}$.

\section{Data collection and definitions}

The PIBS point proposed by Westerveld et al. [4], was defined in the sagittal images. A virtual anteroposterior line was drawn at the level of the inferior border of the symphysis to cross the vertical axis of the uterine tandem, and the following points were marked: PIBS $+2 \mathrm{~cm}$ and PIBS $-2 \mathrm{~cm}$ were defined $2 \mathrm{~cm}$ cranial and caudal to the PIBS, respectively. The point PIBS +2 and PIBS-2 were considered to represent the anatomical middle and introitus part of the vagina [4]. The vaginal reference length (VRL) was defined as the distance from the center of the vaginal sources to the PIBS point.

The rectal (rectovaginal) point and bladder point were also plotted as per the guidelines of International Commission on Radiation Units (ICRU) Report 89 and ICRU Report 38 [8, 9].

Patients underwent a CT scan at the time of the first (BT1) and third (BT3) fractions of BT. BT2, 4 and 5's parameters recorded by taking the dose of average values of BT1 and BT3.

\section{Statistical analysis}

The doses were represented in terms of EQD2, as described above. The SPSS statistical software system (version 18, SPSS, Inc., USA) was used for all statistical analyses. Descriptive statistics were used to indicate mean, median, standard deviation, and range.

\section{Results \\ Demographic and clinical characteristics of the study population}

The demographic and clinical features of the 936 patients are listed in Table 1. Most patients had lesions of stages IIB (455/936, 48.6\%) or IIIB (243/936, 26.0\%). Almost all patients $(929,99.2 \%)$ had squamous cell carcinoma; the remaining seven had adenocarcinoma $(0.8 \%)$. Of the 936 patients, $83(8.8 \%)$ had vaginal involvement (residual disease) at the time of BT, as determined by clinical examination and imaging studies. Most of the residual lesions were localized to the vaginal fornix, or some patients with bulky disease still had 
Table 1 Patient characteristics $(N=936)$

\begin{tabular}{|c|c|}
\hline Characteristics & Value \\
\hline Mean age (range) & $50(25-60)$ y \\
\hline \multicolumn{2}{|l|}{ FIGO stage $(n, \%)$} \\
\hline IB1 & $6(0.6)$ \\
\hline IB2 & $66(7.1)$ \\
\hline$\| \mathrm{A} 1$ & $33(3.5)$ \\
\hline IIA2 & $94(10.0)$ \\
\hline$\| \mathrm{B}$ & $455(48.6)$ \\
\hline$\| I B$ & $243(26.0)$ \\
\hline IVA & $8(0.9)$ \\
\hline IVB & $31(3.3)$ \\
\hline \multicolumn{2}{|l|}{ Histology (n, \%) } \\
\hline Squamous cell carcinoma & $929(99.2)$ \\
\hline Adenocarcinoma & $7(0.8)$ \\
\hline \multicolumn{2}{|l|}{ Dose of EBRT $(n, \%)$} \\
\hline 45Gy & $96(10.3) \mathrm{s}$ \\
\hline 50 Gy & $840(89.7)$ \\
\hline \multicolumn{2}{|l|}{ Dose of BT $(n, \%)$} \\
\hline $24 \mathrm{~Gy}$ & $656(70.1)$ \\
\hline 30 Gy & $280(29.9)$ \\
\hline \multicolumn{2}{|l|}{ Vaginal involvement $(\mathrm{n}, \%)$} \\
\hline Upper third & $83(8.8 \%)$ \\
\hline No involve & $853(91.2 \%)$ \\
\hline \multicolumn{2}{|l|}{ chemotherapy } \\
\hline Yes & $936(100 \%)$ \\
\hline No & $0(0)$ \\
\hline \multicolumn{2}{|l|}{ EBRT } \\
\hline 3D-CRT & 197 (21\%) \\
\hline IMRTNMAT & $739(79 \%)$ \\
\hline \multicolumn{2}{|l|}{ EBRT field } \\
\hline Pelvis field & $924(98.7 \%)$ \\
\hline Extended field & $12(1.3 \%)$ \\
\hline
\end{tabular}

residual disease in the vagina after EBRT. The mean VRL was $4.6 \pm 1.0 \mathrm{~cm}$ (median, $4.5 \mathrm{~cm}$; range, $1.3-8.4$ $\mathrm{cm})$. The distance between two vaginal applicators was $2.8 \pm 0.4 \mathrm{~cm}$ (range, $1.8-4.1 \mathrm{~cm}$ ). The length of the intrauterine catheters was $6.0 \pm 0.6 \mathrm{~cm}$ (range, $3.7-8.5 \mathrm{~cm}$ ).

\section{Dose evaluated at PIBS}

The mean and median summed doses from EBRT and $\mathrm{BT}$ at points PIBS, PIBS $+2 \mathrm{~cm}$, PIBS $-2 \mathrm{~cm}$, and A were expressed as EQD $2_{\alpha / \beta=3}$ (Table 2). Almost all patients received the complete EBRT dose from the upper border of the vagina to the level of the PIBS. The median doses of EBRT at PIBS $+2 \mathrm{~cm}$, PIBS and PIBS- $2 \mathrm{~cm}$ were 50 (45-50) Gy, 50 (45-50) Gy and 0 Gy, respectively. The
Table 2 Summed doses from EBRT and BT in EQD2

\begin{tabular}{|c|c|c|c|}
\hline & $\begin{array}{l}\text { Dose of EBRT } \\
\text { Median } \\
\text { (min-max) }\end{array}$ & $\begin{array}{l}\text { Total dose } \\
(\text { EBRT+BT) } \\
\text { Mean } \pm \text { SD }\end{array}$ & $\begin{array}{l}\text { Total dose } \\
\text { (EBRT+BT) } \\
\text { Median (min-max) }\end{array}$ \\
\hline $\mathrm{A} 1\left(\mathrm{~Gy}, \mathrm{EQD} 2_{\alpha / \beta=10}\right)$ & $50(45-50)$ & $83.3 \pm 2.5$ & $84.0(62.3-90.1)$ \\
\hline $\mathrm{A} 2\left(\mathrm{~Gy}, \mathrm{EQD} 2_{\alpha / \beta=10}\right)$ & $50(45-50)$ & $83.6 \pm 2.5$ & $84.4(72.7-92.6)$ \\
\hline $\mathrm{PIBS}+2\left(\mathrm{~Gy}, \mathrm{EQD} 2_{\alpha / \beta}=3\right)$ & $50(45-50)$ & $99.4 \pm 55.4$ & $82.5(52.7-392.1)$ \\
\hline $\operatorname{PIBS}\left(G y, E Q D 2_{\alpha / \beta=3}\right)$ & $50(45-50)$ & $57.7 \pm 5.2$ & $56.2(51.4-82.1)$ \\
\hline PIBS-2 (Gy,EQD2 $\alpha / \beta=3)$ & 0 & $2.8 \pm 1.1$ & $2.6(0.9-7.4)$ \\
\hline ICRU-R $\left(G y, E Q D 2_{\alpha / \beta}=3\right)$ & - & $79.9 \pm 13.6$ & $77.5(54.8-132.4)$ \\
\hline 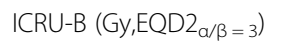 & - & $83.6 \pm 2.54$ & $84.4(72.7-92.6)$ \\
\hline
\end{tabular}

median total $(\mathrm{EBRT}+\mathrm{BT})$ doses in $\mathrm{EQD} 2_{\alpha / \beta=3}$ at PIBS+ $2 \mathrm{~cm}$, PIBS, and PIBS- $2 \mathrm{~cm}$ were 82.5(52.7-392.1) Gy, 56.2(51.4-82.1) Gy, and 2.6(0.9-7.4) Gy, respectively. The median values of the doses administered at points A1 and A2 were 84.0 (62.3-90.1) Gy and 84.4 (72.792.6) Gy, respectively. One center in this study used the dose-volume evaluation system in brachytherapy. However, we used the point A dose-evaluation system to evaluate the BT dose when analyzing the data, so the minimum dose in point $\mathrm{A}$ was quite low.

\section{Comparison between two groups with different VRL}

Patients were classified into two groups based on a cutoff VRL of $4.5 \mathrm{~cm}$; one group included patients with a VRL $\leq 4.5 \mathrm{~cm}$ and the other patients with a VRL $>4.5$ $\mathrm{cm}$. The mean total dose of EBRT $+\mathrm{BT}$ administered at points PIBS $+2 \mathrm{~cm}$, PIBS, and PIBS $-2 \mathrm{~cm}$ in the two groups are shown in Table 3. Large variations were noted between the two groups in the total $(\mathrm{EBRT}+\mathrm{BT})$ doses in EQD $2_{\alpha / \beta=3}$ at these three PIBS levels. The analysis of dose variation at the PIBS points according to the VRL (Fig. 1) showed that a shorter VRL resulted in a higher total dose at point PIBS $+2 \mathrm{~cm}$ and PIBS; in fact, the dose at the PIBS $+2 \mathrm{~cm}$ point showed significant changes with differing VRL, although the dose at the PIBS- $2 \mathrm{~cm}$ point did not show any marked changes with differing VRL. However, the PIBS point showed only moderate changes with differing VRL. Once the VRL

Table 3 Total (EBRT+BT) doses at PIBS $+2 \mathrm{~cm}$, PIBS and PIBS-2 $\mathrm{cm}$ according to a VRL cut-off of $4.5 \mathrm{~cm}$

\begin{tabular}{|c|c|c|c|}
\hline & \multicolumn{2}{|c|}{$\begin{array}{l}\text { Total dose }(\text { EBRT+BT) } \\
\text { Mean } \pm \text { SD }\end{array}$} & \multirow[t]{2}{*}{$P$} \\
\hline & $\mathrm{VRL} \leq 4.5 \mathrm{~cm}$ & VRL $>4.5 \mathrm{~cm}$ & \\
\hline $\mathrm{PIBS}+2 \mathrm{~cm}\left(\mathrm{~Gy}, \mathrm{EQD} 2_{\alpha / \beta=3}\right)$ & $128.5 \pm 64.2$ & $68.9 \pm 11.9$ & $<0.01$ \\
\hline $\operatorname{PIBS}\left(\mathrm{Gy}, \mathrm{EQD} 2_{\alpha / \beta=3}\right)$ & $60.7 \pm 5.5$ & $54.5 \pm 1.8$ & $<0.01$ \\
\hline PIBS-2 cm (Gy, EQD $\left.2_{\alpha / \beta}=3\right)$ & $0.8 \pm 0.3$ & $0.5 \pm 0.1$ & $<0.01$ \\
\hline ICRU-R (Gy, EQD2 $\left.2_{\alpha / \beta=3}\right)$ & $82.0 \pm 14.1$ & $77.6 \pm 12.9$ & $<0.01$ \\
\hline ICRU-B (Gy, EQD2 $\alpha / \beta=3)$ & $85.0 \pm 13.6$ & $79.8 \pm 13.2$ & $<0.01$ \\
\hline
\end{tabular}




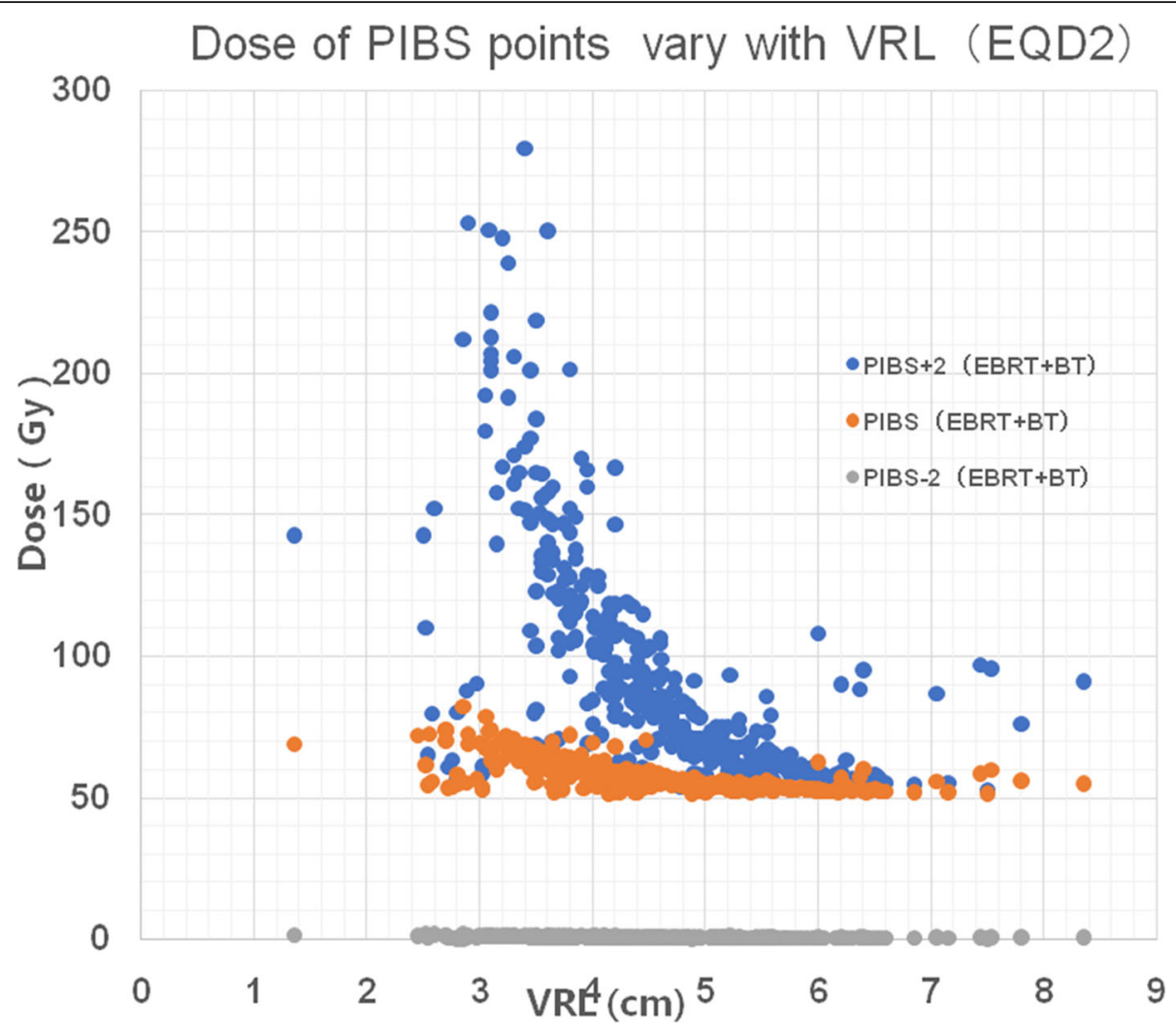

Fig. 1 Scatter diagram showing that the doses at PIBS points varied with the VRL. The dose at the PIBS $+2 \mathrm{~cm}$ point changed steeply, while the dose at PIBS-2 cm changed only slightly with increasing VRL. The change in the PIBS dose was moderate

value increased to more than $4.5 \mathrm{~cm}$, the dose value stabilized.

Considerable dose variation was seen at both levels. The mean total doses in the VRL $\leq 4.5 \mathrm{~cm}$ and VRL > $4.5 \mathrm{~cm}$ groups were $128.5 \mathrm{~Gy}$ and $68.9 \mathrm{~Gy}$ at point PIBS+
$2 \mathrm{~cm}, 60.7 \mathrm{~Gy}$ and $54.5 \mathrm{~Gy}$ at point PIBS, and $0.8 \mathrm{~Gy}$ and 0.5 Gy at point PIBS- $2 \mathrm{~cm}$, respectively. Figure 2 clearly shows that when the VRL $=4.5 \mathrm{~cm}$, the PIBS $+2 \mathrm{~cm}$ point was located between the $75 \%$ isodose line and $50 \%$ isodose line; when the VRL $>4.5 \mathrm{~cm}$, the PIBS $+2 \mathrm{~cm}$ point

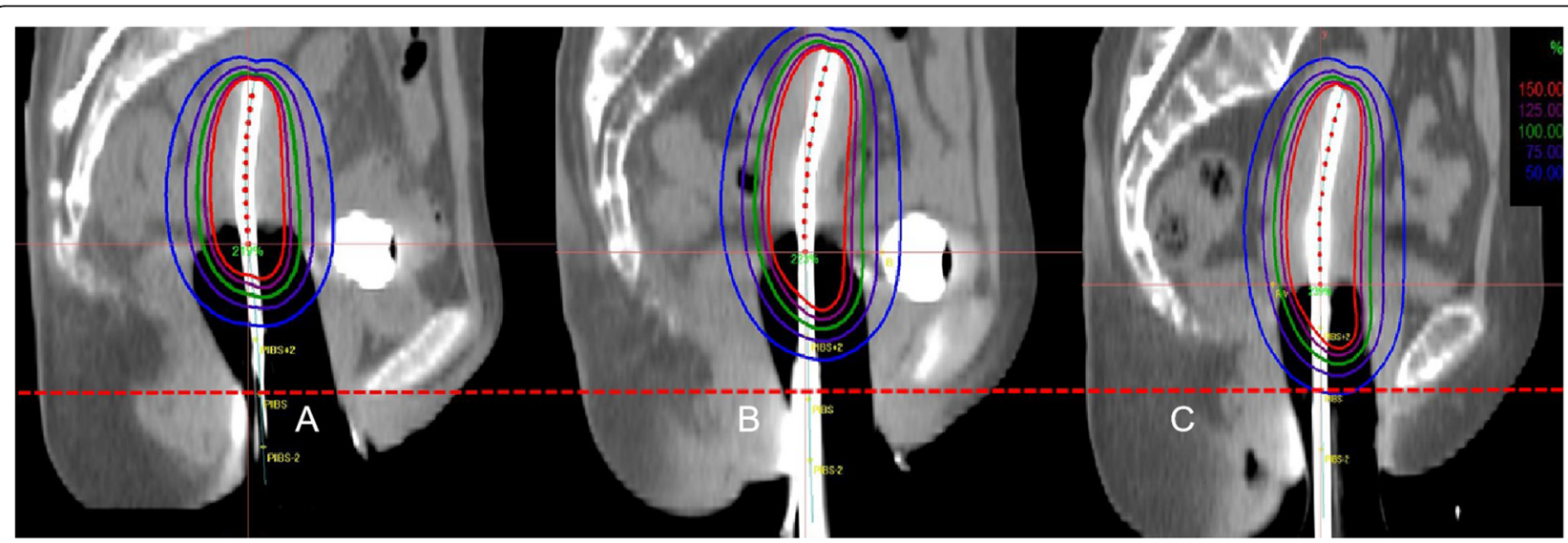

Fig. 2 BT CT sagittal view for a patient with tandem and ovoid applicator. The picture shows three cases of BT planning for three patients with different VRLs. a: Patient with a VRL of $6.8 \mathrm{~cm}$. b: Patient with a median VRL of $4.5 \mathrm{~cm}$. c: Patient with a VRL of $3.5 \mathrm{~cm}$, in whom the PIBS+2 cm point was located in the high dose area. Red contour: the 150\% isodose line. Green contour: the 100\% isodose line. Red dashes: level of PIBS points. Yellow dot: PIBS $+2 \mathrm{~cm}$ point. With a shorter VRL, the PIBS $+2 \mathrm{~cm}$ point becomes closer to the vaginal applicator. Definition of the PIBS +2 $\mathrm{cm}$ is not applicable anymore 
was located out of the $50 \%$ isodose line; and when the VRL $<4.5 \mathrm{~cm}$, the PIBS $+2 \mathrm{~cm}$ point was located within the $100 \%$ isodose line.

\section{Comparison between two fractions of BT}

Patients underwent CT localization at the time of BT fractions 1 and 3, and the dosage values of PIBS, PIBS \pm $2 \mathrm{~cm}$, ICRU-R, and ICRU-B points obtained at BT1 and BT3 were recorded, as shown in Table 4. All the parameters in the two fractions were similar and showed no difference between BT1 and BT3 $(P>0.05)$.

\section{Discussion}

The dose administered at the target area and the irradiation volume are closely related to the occurrence of radiotherapy-related injury of the rectum and bladder; accordingly, some restrictions have been established for safe dosage amounts of radiation for the rectum and bladder $[10,11]$. Similar to the case in bladder and rectal, radiotherapy-induced injury in the vagina may occur at any time within the first 2 years of radiation treatment. A new method for dose evaluation in the vagina using the PIBS points was recently proposed by the EMBRACE study [12]. In the PIBS system, the dose variations at PIBS points are determined by the demarcation of the EBRT border, the extent of vaginal involvement at the time of BT and the VRL [4]. Our findings suggest that this method of assessing the total EBRT and BT dose administered in the upper, middle (PIBS+ $2 \mathrm{~cm}$ ), and lower (PIBS and PIBS-2 cm) parts of the vagina is applicable even in a multicenter setting. In our cohort, the lower border for the EBRT field was located approximately at the level of the PIBS or below; thus, the vagina above the PIBS level received a radiation dose of $50 \mathrm{~Gy}$ from EBRT. Variations in the dose administered to the upper segment of the vagina can be mainly attributed to variations in the $\mathrm{BT}$ dose. And at the time of $\mathrm{BT}$, the residual lesions were mainly localized at the level of the

Table 4 Comparison of parameters between BT1 and BT3

\begin{tabular}{|c|c|c|c|}
\hline & BT1 & BT3 & $P$-value \\
\hline Oviods distance $(\mathrm{cm})$ & 2.8 & 2.8 & 0.614 \\
\hline Tandem length $(\mathrm{cm})$ & 6.0 & 6.1 & 0.105 \\
\hline VRL $(\mathrm{cm})$ & 4.5 & 4.5 & 0.947 \\
\hline $\mathrm{A} 1\left(\mathrm{~Gy}, \mathrm{EQD} 2_{\alpha / \beta=10}\right)$ & 7.9 & 7.9 & 0.637 \\
\hline $\mathrm{A} 2\left(\mathrm{~Gy}, \mathrm{EQD} 2_{\alpha / \beta=10}\right)$ & 8.0 & 8.0 & 0.242 \\
\hline $\mathrm{PIBS}+2 \mathrm{~cm}\left(\mathrm{~Gy}, \mathrm{EQD} 2_{\alpha / \beta}=3\right)$ & 12.6 & 18.3 & 0.124 \\
\hline $\operatorname{PIBS}\left(G y, E Q D 2_{\alpha / \beta}=3\right)$ & 1.9 & 2.0 & 0.478 \\
\hline $\mathrm{PIBS}-2 \mathrm{~cm}\left(\mathrm{~Gy}, \mathrm{EQD} 2_{\alpha / \beta}=3\right)$ & 0.6 & 0.7 & 0.128 \\
\hline ICRU-R $\left(G y, E Q D 2_{\alpha / \beta=3}\right)$ & 7.4 & 7.3 & 0.743 \\
\hline 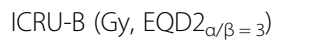 & 7.1 & 6.5 & 0.064 \\
\hline
\end{tabular}

vaginal fornix. This implies that the VRL plays an important role in the dose variation at the PIBS.

It is obvious that the VRL value of Chinese patients is much shorter than that reported by studies conducted in other regions. Accordingly, the median VRL among our patients was $4.5(1.3-8.4) \mathrm{cm}$, which is considerably different from the VRL $6.1(1.6-11.0) \mathrm{cm}$ reported in 2013 and 5.4 (1.0-8.3) $\mathrm{cm}$ in 2016 on conventional radiographsin by Westerveld et al. $[4,13]$. The value of VRL depends on many factors, such as genetic, ethnic, geographical $[14,15]$, the residual lesions and the position of the vaginal applicator at time of BT. For instance, a large remnant tumor mass after EBRT may decrease the VRL. Radiotherapy (EBRT) may lead to vascular toxicity and fibrosis, rendering the vagina short and narrow [16].. Berger et al. concluded that geometrical shifts of even $1 \mathrm{~mm}$ lead to a $25 \%$ change in the estimated dose to the vagina [17]. Therefore, BT was performed after EBRT. The vaginal applicator was placed and fixed firmly, as better repeatability among every fraction of BT can reduce dose variations at the PIBS. In our study, statistical analysis showed no significant difference between the doses of the two fractions of BT. In the present study, we selected patients of age $\leq 60$ years because age is also a factor that can affect the VRL, as the VRL decreases with age. .

Interestingly, the median doses reported in our series differed from those reported in the series by Westerveld et al. $[4,16]$ (Table 5). At point PIBS $+2 \mathrm{~cm}$, the median total (EBRT + BT) doses reported by Westerveld et al. in their 2013 and 2016 studies were 49.6 (32.1-89.6) Gy and 54 (32-109) Gy, respectively, whereas that in our study was 82.5 (52.7-392.1) Gy. Thus, compared to their results, ours showed that the dose at PIBS $+2 \mathrm{~cm}$ was 30 Gy higher. At the PIBS point, the values in Westerveld et al. studies were 36.7 (3.1-68.2) Gy and 41 (3-81) Gy, respectively, whereas that in our study was 56.2 (51.482.1) Gy. Thus, the dose at point PIBS in our study was equivalent to the dose reported for the PIBS $+2 \mathrm{~cm}$ point by Westerveld et al. Because the VRL in the Chinese women included in our study was $1.5-2 \mathrm{~cm}$ less than that reported for European patients, more volume of the vagina received high-dose radiation. Further, the PIBS-2 $\mathrm{cm}$ point represents the level of the vaginal introitus, and the dose values observed here indicate that patients received extremely low doses at this level that did not

Table 5 Comparison in PIBS points

\begin{tabular}{lll}
\hline & \multicolumn{2}{l}{ Total dose (EBRT+BT) Median (min-max) } \\
\cline { 2 - 3 } & Westerveld.H & Our Study \\
\hline PIBS+ 2 (Gy,EQD2 $\alpha / \beta=3)$ & $50(32-90)$ & $82.5(52.7-392.1)$ \\
PIBS $\left(G y, E Q D 2_{\alpha / \beta=3}\right)$ & $37(3-68)$ & $56.2(51.4-82.1)$ \\
PIBS-2 $\left(G y, E Q D 2_{\alpha / \beta=3}\right)$ & $4(1-46)$ & $2.6(0.9-7.4)$ \\
\hline
\end{tabular}


cause serious radiation injury in most cases. Figure 1 shows that the dose at the PIBS $+2 \mathrm{~cm}$ point varied drastically with differing VRL on account of near of the source. However, dose changes at the PIBS point with variation in the VRL were moderate. So the PIBS point could be considered as a good indicator of the radiation dose applied to the vagina and predictor of late morbidity caused by high-dose exposure of the vagina, especially in patients with a VRL shorter than $4.5 \mathrm{~cm}$.

The above-mentioned findings can be explained by a few points. First, the VRL is the basis of the dose determination using the PIBS system. Second, the type of applicator used may influence the dose received by the vagina. In the multicenter study by Westerveld et al., it was evident that different applicators led to variation in the radiation dose applied at the vaginal wall. For example, the tandem-ovoid applicator normally administers higher doses at the anterior and posterior vaginal walls as compared to the tandem-ring applicators, whereas the latter administers higher doses at the lateral wall of the upper part of the vagina as compared to the former [9]. Third, the application of the point A dose evaluation system, which is different from the dose-volume evaluation system used in studies from other countries, may also influence the vaginal doses received. This is evident from the fact that our patients received a higher vaginal dose as compared with those reported in other studies.

To better understand the correlation of the VRL and dose variation at the PIBS system points, we classified our patients into two groups according to the median value of VRL, which was $4.5 \mathrm{~cm}$. The results indicated significant differences in the dose values for patients with a VRL $\leq 4.5 \mathrm{~cm}$ versus a VRL $>4.5 \mathrm{~cm}$. Thus, for patients with a short $(<4.5 \mathrm{~cm}) \mathrm{VRL}$, a greater volume of the vagina was exposed to high doses. This would mean an increased risk of vaginal morbidity in the future.

Our study has a few limitations. First, we used the point A dose-evaluation system to evaluate the BT dose. The dose for the vagina and surrounding OARs may have been lower if we had used the dose-volume evaluation system, especially in cases of large tumors. Second, patients underwent a CT scan only at the time of the first (BT1) and third (BT3) fractions of BT, and using the average values of the BT1 and BT3 for evaluating the other parameters. Therefore, some deviation is possible. Lastly, we only assessed the vaginal dose in cervical cancer using the new evaluation system and did not evaluate the data of incidence of vaginal toxicity. Further studies are required to clarify these issues.

\section{Conclusions}

This observational study indicated that the radiation dose administered at the PIBS points differs significantly with variation in the VRL and that the VRL values for Chinese women were much less than those for European and American women. Therefore, Chinese patients with cervical cancer received higher radiation doses for total EBRT and BT in the upper $2 / 3$ of the vagina when using the PIBS evaluation system. Therefore, it is important to pay attention to the radiation dose received by the vaginal region in order to reduce vaginal radiation injury. The findings of this study provide the basis for the efficient use of PIBS in the evaluation of the vaginal radiation dose in Chinese patients. Further studies are necessary to correlate these parameters with vaginal morbidity.

\section{Abbreviations \\ PIBS: Posterior-inferior border of symphysis; FIGO: International Federation of Gynecology and Obstetrics; EBRT: External-beam radiotherapy; \\ BT: Brachytherapy; 3DCRT: 3D-conformal radiotherapy; IMRT: Intensity- modulated radiotherapy; RTOG: Radiation Therapy Oncology Group; 3D: Three-dimensional; CT: Computed tomography; HDR: High-dose rate; SIM: Simulation; VRL: Vaginal reference length; ICRU: International Commission on Radiation Units}

\section{Acknowledgements}

We thank the patients who participated in this study.

\section{Authors' contributions}

Data Collection, Statistical Analysis, Data Analysis \& Interpretation, Manuscript Preparation: JW, KZ, TW. Conception \& Design of Study, data analysis \& interpretation, senior reviewer: ZL Data analysis \& interpretation: RW, WY. Data collection \& interpretation, reviewer: FZ, LY, LR, JH, YW, LW, MS, GW, CW, QK, JY, SL, FY, BL, JL, FS, JS. Manuscript Preparation \& Editor: EKD. All authors have read and approved the manuscript, and ensure that this is the case.

\section{Funding}

This work was supported in collection and analysis of data and in writing the manuscript by grants from the National Science Foundation of China (\#81602676).

\section{Availability of data and materials}

The datasets used and/or analyzed during the current study are available from the corresponding author on reasonable request.

\section{Ethics approval and consent to participate}

The study was approved by the ethics committee of the First Affiliated Hospital of Xi'an Jiaotong University (No. XJTU1AF2017LSK-11). Informed consent was written and obtained from all patients who participated in this study.

Consent for publication

Not applicable.

\section{Competing interests}

The authors declare that they have no competing interests.

\section{Author details}

'Department of Radiation Oncology, The First Affiliated Hospital of Xi'an Jiao Tong University, 277\# West Yanta Road, Xi'an, Shaanxi, China. ${ }^{2}$ Department of Radiation Oncology, Peking Union Medical College Hospital, Chinese

Academy of Medical Sciences and Peking Union Medical College, Beijing 100032, China. ${ }^{3}$ Department of Oncology, The Affiliated Hospital of Guizhou Medical Universty/Guizhou Cancer Hospital, Gui Yang 550000, China.

${ }^{4}$ Department of Radiation Oncology, General Hospital of Ningxia Medical University, Yin chuan 750004, China. ${ }^{5}$ Department of Radiation Oncology, The Second Affiliated hospital of Xi'an Jiao Tong University, Xi'an 710004, China. ${ }^{6}$ Department of Radiation Oncology, First Affiliated Hospital of Air 
Force Medical University, Xi'an 710032, China. 'Department of Gynecology Oncology, Shaanxi Provincial Tumor Hospital, Xi'an 710061, China.

${ }^{8}$ Department of Radiation Oncology, The first people's Hospital of Kashi District, Xinjiang 844000, China. ${ }^{9}$ Department of Radiation Oncology, People's Hospital of Xinjiang Uygur Autonomous Region, Urumchi 830002, China. ${ }^{10}$ Department of Radiation Oncology, The 940th Hospital of Joint Logistics Support force of Chinese People's Liberation Army, Lan Zhou 730050, China. ${ }^{11}$ Department of Oncology, Guizhou Provincial People's Hospital, Guiyang 550002, China. ${ }^{12}$ Department of Radiation Oncology, The Second Affiliated Hospital of Shaanxi University of Chinese Medicine, Xian yang 712046, China. ${ }^{13}$ Department of Radiation Oncology, Xi'an Gao Xin Hospital, Xi'an 710000, China.

Received: 21 May 2019 Accepted: 3 December 2019

Published online: 16 December 2019

\section{References}

1. Zhang KS, Liu Z, Wang T, Wang J, Su J, Shi F, et al. Occurrence of radiationinduced injury in vagina after radical radiotherapy of cervical cancer and its affecting factors. Zhonghua Fu Chan Ke Za Zhi. 2018;53(4):257-62.

2. Kirchheiner $K$, Nout RA, Lindegaard JC. Haie-Meder, Mahantshetty U, Segedin B, et al. dose-effect relationship and risk factors for vaginal stenosis after definitive radio (chemo) therapy with image-guided brachytherapy for locally advanced cervical cancer in the EMBRACE study. Radiother Oncol. 2016;118(1):160-6.

3. Susko M, Craciunescu O, Meltsner S, Yang Y, Steffey B, Cai J, et al. Vaginal dose is associated with toxicity in image guided tandem ring or ovoidbased brachytherapy. Int J Radiat Oncol Biol Phys. 2016;94(5):1099-105.

4. Westerveld H, Pötter R, Berger D, Dankulchai P, Dörr W, Sora MC, et al. Vaginal dose point reporting in cervical cancer patients treated with combined 2D/3D external beam radiotherapy and 2D/3D brachytherapy. Radiother Oncol. 2013;107(1):99-105.

5. FIGO committee on gynecology oncology. Revised FIGO staging for carcinoma of the vulva, cervix, and endometrium. Int J Gynaecol Obstet. 2009;105(2):103-4.

6. Zahra MA, Taylor A, Mould G, Coles C, Crawford R, Tan LT. Concurrent weekly cisplatin chemotherapy and radiotherapy in a haemodialysis patient with locally advanced cervix cancer. Clin Oncol (R Coll Radiol). 2008;20(1):6-11.

7. Lim K, Small W Jr, Portelance L, Creutzberg C, Jürgenliemk-Schulz IM, Mundt A, et al. Consensus guidelines for delineation of clinical target volume for intensity-modulated pelvic radiotherapy for the definitive treatment of cervix cancer. Int J Radiat Oncol Biol Phys. 2011;79(2):348-55.

8. Prescribing, Recording, and Reporting Brachytherapy for Cancer of the Cervix. J ICRU. 2013;13(1-2):NP. https://doi.org/10.1093/jicru/ndw027.

9. International Commission on Radiation Units and Measurements. Report No 38: dose and volume specifications for reporting intracavitary therapy in gynecology. Bethesda: ICRU; 1985[R].

10. Koom WS, Sohn DK, Kim JY, Kim JW, Shin KH, Yoon SM, et al. Computed tomography-based high-dose-rate Intracavitary brachytherapy for uterine cervical Cancer: preliminary demonstration of correlation between dosevolume parameters and rectal mucosal changes observed by flexible Sigmoidoscopy. Int J Radiat Oncol Biol Phys. 2007;68(5):1446-54.

11. Georg P, Potter R, Georg D, Lang S, Dimopoulos JC, Sturdza AE, et al. Dose effect relationship for late side effects of the rectum and urinary bladder in magnetic resonance image-guided adaptive cervix cancer brachytherapy. Int J Radiat Oncol Biol Phys. 2012;82(2):653-7.

12. EMBRACE, International MRI-guided Brachytherapy in cervical cancer, https://www.embracestudy.dk

13. Westerveld H, de Leeuw A, Kirchheiner K, Dankulchai P, Oosterveld B, Oinam A, et al. Multicentre evaluation of a novel vaginal dose reporting method in 153 cervical cancer patients. Radiother Oncol. 2016;120(3):420-7.

14. Hirschhorn JN, Lindgren CM, Daly MJ, Kirby A, Schaffner SF, Burtt NP, et al. Genomewide linkage analysis of stature in multiple populations reveals several regions with evidence of linkage to adult height. Am J Hum Genet. 2001;69(1):106-16.

15. Stulp G, Barrett L. Evolutionary perspectives on human height variation. Biol Rev Camb Philos Soc. 2016;91(1):206-34.

16. Kirchheiner K, Fidarova E, Nout RA, Schmid MP, Sturdza A, Wiebe E, et al. Radiation-induced morphological changes in the vagina. Strahlenther Onkol. 2012;188(11):1010-9.
17. Berger D, Dimopoulos J, Georg P, Georg D, Pötter R, Kirisits C. Uncertainties in assessment of the vaginal dose for intracavitary brachytherapy of cervical cancer using a tandem-ring applicator. Int J Radiat Oncol Biol Phys. 2007; 67(5):1451-9.

\section{Publisher's Note}

Springer Nature remains neutral with regard to jurisdictional claims in published maps and institutional affiliations.
Ready to submit your research? Choose BMC and benefit from:

- fast, convenient online submission

- thorough peer review by experienced researchers in your field

- rapid publication on acceptance

- support for research data, including large and complex data types

- gold Open Access which fosters wider collaboration and increased citations

- maximum visibility for your research: over $100 \mathrm{M}$ website views per year

At BMC, research is always in progress.

Learn more biomedcentral.com/submissions 